\title{
Enhancement of humoral and cell mediated immune response to HPV16 L1-derived peptides subsequent to vaccination with prophylactic bivalent HPV L1 virus-like particle vaccine in healthy females
}

\author{
MASATO YOKOMINE $^{1}$, SATOKO MATSUEDA ${ }^{2,5}$, KOUICHIRO KAWANO ${ }^{1}$, TETSURO SASADA ${ }^{2,6}$, \\ AKIMASA FUKUI $^{1}$, TAKUTO YAMASHITA ${ }^{3}$, NOBUKAZU KOMATSU ${ }^{4}$, SHIGEKI SHICHIJO $^{2}$, \\ KAZUTO TASAKI $^{1}$, KEN MATSUKUMA ${ }^{1}$, KYOGO ITOH ${ }^{2}$, TOSHIHARU KAMURA ${ }^{1,7}$ and KIMIO USHIJIMA ${ }^{1}$ \\ ${ }^{1}$ Department of Obstetrics and Gynecology, Kurume University School of Medicine, Kurume, Fukuoka 830-0011; \\ ${ }^{2}$ Cancer Vaccine Center, Kurume University Medical Center, Kurume, Fukuoka 839-0863; ${ }^{3}$ Biostatistics Center \\ and ${ }^{4}$ Department of Immunology, Kurume University School of Medicine, Kurume, Fukuoka 830-0011, Japan
}

Received December 1, 2015; Accepted November 25, 2016

DOI: $10.3892 /$ etm.2017.4150

\begin{abstract}
Currently prophylactic HPV16/18 L1 virus-like particle (VLP) vaccines are employed with great success for the prevention of HPV infection. However, limited information is available regarding the immune responses against human papillomavirus (HPV) 16/18 L1 subsequent to HPV16/18 L1 VLP vaccination, primarily due to the lack of widely used assays for immune monitoring. The aim of the present study was to identify HPV16 L1-derived B and T cell epitopes for monitoring the immune responses after HPV16/18 L1 VLP vaccination in healthy females. The levels of immunoglobulin $\mathrm{G}(\mathrm{IgG}), \operatorname{IgE}$, IgA and IgM reactive to HPV16 L1-derived peptides were measured by multiplex bead suspension assay. Following detailed B cell epitope mapping, T cell responses specific to HPV16 L1-derived peptides were evaluated by an IFN- $\gamma$ ELISPOT assay. The levels of IgG, IgM and IgA reactive to 20-mer peptides (PTPSGSMVTSDAQIFNKPYW)
\end{abstract}

Correspondence to: Dr Kouichiro Kawano, Department of Obstetrics and Gynecology, Kurume University School of Medicine, 67 Asahi-machi, Kurume, Fukuoka 830-0011, Japan

E-mail: kawano_kouichirou@kurume-u.ac.jp

Present addresses: ${ }^{5}$ Center for Immunotherapy, Roswell Park Center Institute, Buffalo, NY 14263, USA; ${ }^{6}$ Cancer Vaccine Center, Kanagawa Cancer Center, Yokohama, Kanagawa 241-8515; ${ }^{7}$ Department of Obstetrics and Gynecology, Yanagawa Hospital, Yanagawa, Fukuoka 832-0077, Japan

Abbreviations: HPV, human papillomavirus; VLP, virus-like particle; HLA, human leukocyte antigen; FIU, fluorescent intensity units

Key words: human papillomavirus, prophylactic vaccine, B cell epitope, $\mathrm{T}$ cell epitope at positions 293-312 and 300-319 of HPV16 L1 were significantly increased in the plasma after 2, 7, and 12 months after first vaccination. Detailed epitope mapping identified the amino acid sequence (TSDAQIFNKP) at position 301-310 of HPV16 L1 as an immunogenic B cell epitope. In addition, $\mathrm{T}$ cell responses to an HLA-A2- and HLA-A24-restricted epitope (QIFNKPYWL) at position 305-313 of HPV16 L1 were increased following immunization, suggesting that the HPV16/18 L1-VLP vaccination as able to induce specific immune responses in $\mathrm{T}$ and $\mathrm{B}$ cells simultaneously. The identified $\mathrm{B}$ and $\mathrm{T}$ cell epitopes may be useful as a biomarker for monitoring the immune responses subsequent to HPV16/18 L1 VLP vaccination. Thus, the present study may provide novel information to improve the understanding of the immune responses to HPV16 L1.

\section{Introduction}

Cervical cancer is the fourth most prevalent cancer in women worldwide (1). The main cause of this disease has been known to be an infection of specific types of human papillomavirus (HPV), including HPV types 16 and 18 (2,3). Global epidemic studies of cervical screening with cervical cytology have demonstrated its efficacy. The greatest decline in cervical cancer-associated mortality was 3\% per year between 1950 and 1970 (4). Currently, prophylactic HPV16/18 L1-virus-like particle (VLP) vaccines, which induce neutralizing antibody responses $(5,6)$, have also been used with great success and show extremely high preventive effect against HPV16/18 infection $(7,8)$. For instance, the preventive effect of the HPV16/18 L1-VLP vaccines has been reported to last up to 8.4 years $(9,10)$. Nevertheless, only limited information is currently available regarding the immune responses against HPV16/18 L1, primarily due to the lack of widely used assays for immune monitoring $(11,12)$. Several assays, such as pseudovirion-based neutralization assay, enzyme-linked immunosorbent assay, competitive luminex immunoassay, and the in situ-purified 
gluthione-S-transferase L1 fusion protein-based multiplex immunoassay (GST-L1 MIA), have been developed to monitor antibody responses to HPV (13-16). However, no standardized serological assay is currently available for the assessment of HPV-specific antibody responses, particularly for large scale examination. Therefore, the biomarkers to precisely monitor the effects of HPV16/18 L1-VLP vaccines remain to be identified.

In the present study, B and T cell responses to HPV16/18 L1 were investigated in healthy females in order to identify a biomarker for monitoring immune responses subsequent to the HPV16/18 L1-VLP vaccination.

\section{Materials and methods}

Immunization with the bivalent HPV16/18 L1-VLP vaccine and sample collection. The present study was approved by the Kurume University Ethical Committee (Kurume, Japan). After a full explanation of the protocol, a written informed consent was obtained from 10 healthy females prior to enrollment. The enrolled females, who were aged between 23 and 33 years with a mean age of $25.5 \pm 2.9$ years, had a human leukocyte antigen (HLA) -A2 and/or HLA-A24. They were not subjected to cervical cytology examination or an HPV DNA test prior to participation to the present study as titration of neutralizing antibody against HPV is undetectable in 50\% of infected women and is at a low level if detected. In addition, obtaining a cervical sample would cause an unnecessary burden to these healthy young women. The participants received intramuscular injection $(0.5 \mathrm{ml})$ of the bivalent HPV16/18 L1-VLP vaccine (Cervarix ${ }^{\circledR}$; GlaxoSmithKline, London, UK), which contained HPV16 L1-VLP $(20 \mu \mathrm{g})$ and HPV18 L1-VLP $(20 \mu \mathrm{g})$ mixed with AS04 adjuvant [aluminum hydroxide $(500 \mu \mathrm{g})$ and 3 -deacylated monophosphoryl lipid A $(50 \mu \mathrm{g})]$. The vaccine was administered in three doses at 0,1 and 6 months. In all cases, $20 \mathrm{ml}$ of peripheral blood was collected prior to immunization and at 1, 2, 7, 12 and 18 months after the first immunization. Plasma was separated from whole blood and frozen at $-80^{\circ} \mathrm{C}$ until further use. Peripheral blood mononuclear cells (PBMCs) were obtained by Ficoll-Paque Plus (GE Healthcare, Uppsala, Sweden) density gradient centrifugation, and cryopreserved until further use.

Peptides. In total, 10 different HPV16 L1-derived peptides (20-mer) with binding motifs to both HLA-class I (A2 or A24) and HLA-class II (DR) were selected using MULTIPRED web software (antigen.i2r.a-star.edu.sg/multipred/; accessed on 12 Feburary 2012), as reported previously (17), and are listed in Table I. For epitope mapping, 8 different 10-mer overlapping peptides were selected from the amino acid sequence from positions 295 to 325 of HPV16 L1. The synthetic peptides were purchased from Greiner Bio-One (Thermo Fisher Scientific, Inc., Waltham, MA, USA). Each peptide was dissolved in dimethyl sulfoxide, and stored at $-80^{\circ} \mathrm{C}$ until use in further experiments.

Measurement of immunoglobulin (Ig) levels reactive to HPV-16L1-derived peptides. The Ig levels reactive to HPV16L1-derived peptides were measured by multiplex bead suspension array using the Luminex system (Luminex Corp.,
Austin, TX, USA) as previously described (18). In order to detect peptide-specific $\operatorname{IgG}, \operatorname{IgM}$ and $\operatorname{IgE}$ levels, the beads were washed with wash buffer (0.05\% Tween-20 in PBS) and incubated with $100 \mu$ of biotinylated goat anti-human $\mathrm{IgG}$ (1:200; BA-3080), biotinylated goat anti-human $\operatorname{IgM}(1: 200$; BA-3020; both Vector Laboratories Inc., Burlingame, CA, USA) or biotinylated goat anti-human IgE (1:200; AHI0509; BioSource; Thermo Fisher Scientific, Inc.) antibodies for $1 \mathrm{~h}$ at $30^{\circ} \mathrm{C}$. To detect peptide-specific IgA, the beads were incubated with $100 \mu \mathrm{l}$ goat anti-human IgA antibody (1:200; A80-102A; Bethyl Laboratories, Inc., Montgomery, TX, USA) for $1 \mathrm{~h}$ at $30^{\circ} \mathrm{C}$, followed by washing and subsequent incubation with $100 \mu \mathrm{l}$ of biotinylated rabbit anti-goat IgG antibody (1:200; 55366; Cappel, MP Biomedicals, LLC, Solon, OH, USA) for $30 \mathrm{~min}$ at $30^{\circ} \mathrm{C}$. Following washing, the beads were incubated with $100 \mu \mathrm{l}$ of streptavidin-PE (1:200; S-866; Molecular Probes; Thermo Fisher Scientific, Inc.) for $30 \mathrm{~min}$ at $30^{\circ} \mathrm{C}$, followed by washing and detection of fluorescence intensity units on the beads using the Luminex system (18).

Measurement of $T$ cell responses to an HPV-16L1-derived peptide. T cell responses specific to HPV16 L1-derived peptides were evaluated by IFN- $\gamma$ ELISPOT assay (8223; Medical \& Biological Laboratories Co., Ltd., Nagoya, Japan). Briefly, PBMCs $\left(2 \times 10^{5}\right.$ cells/well) isolated from whole peripheral blood samples of the participants were cultured with $10 \mu \mathrm{g} / \mathrm{ml}$ of synthetic peptides in 96 round well plates (Nunc; Thermo Fisher Scientific, Inc.) in $200 \mu \mathrm{l}$ culture medium containing 45\% AIM-V (Thermo Fisher Scientific, Inc.), 45\% RPMI-1640 (Thermo Fisher Scientific, Inc.), 10\% FBS (MP Biomedicals, Solon, OH, USA), $20 \mathrm{IU} / \mathrm{ml}$ interleukin-2 (Bio-Rad Laboratories, Inc., Hercules, CA, USA) and 0.1 mM MEM non-essential amino acid solution (Thermo Fisher Scientific, Inc.). Half of the medium was replaced with new medium containing the peptide $(20 \mu \mathrm{M})$ at every 3 or 4 days. After 5 stimulations, T cells were stimulated with peptide-pulsed T2 cells (ATCC, Manassas, VA, USA) or C1R-A24 cells (kindly provided by Dr Masafumi Takiguchi, Kumamoto University, Kumamoto, Japan), and IFN- $\gamma$ production in response to the specific peptide was determined in comparison with the response to irrelevant peptide. Cells were also tested for IFN $-\gamma$ production in response to a negative control peptide, HLA-A2 rescticted peptide (SLYNTVATL, synthesized; Greiner Bio-One, Kremsmünster, Austria) from human immunodeficiency virus (HIV) or HLA-A24 restricted HIV peptide (RYLRQQLLGI, synthesized; Greiner Bio-One). HIV peptides were used as negative control peptides since these peptides were irrelevant to HPV. Spot numbers of IFN- $\gamma$-secreting cells after 18-h incubation were determined by ELISPOT assay with an ELISPOT reader (ImmunoSpot S5 Versa Analyzer; Cellular Technology Ltd., Shaker Heights, OH, USA). All assays were performed in duplicate. Peptide-specific $\mathrm{T}$ cell responses were shown as the differences between the spot numbers per $1 \times 10^{5}$ PBMCs in response to the specific peptide and those in response to the control peptide. When the PBMCs from females with both HLA-A2 and HLA-A24 were used, mean values of spot numbers from the culture with peptide-pulsed $\mathrm{T} 2$ cells and those with peptide-pulsed C1R-A24 cells were used for calculation. PBMCs were available for this analysis in only 9 of 10 individuals at 2 months after vaccination, but were 
Table I. HPV16 L1-derived peptides used in the present study and their binding motifs to HLA-A2 and HLA-A24.

\begin{tabular}{|c|c|c|c|c|c|c|c|c|}
\hline \multirow[b]{2}{*}{ Peptide } & \multicolumn{2}{|r|}{ HLA-DR } & \multicolumn{2}{|c|}{ HLA-A2 } & \multirow[b]{2}{*}{ Score } & \multicolumn{3}{|c|}{ HLA-A24 } \\
\hline & Position & Sequence & Position & Sequence & & Position & Sequence & Score \\
\hline Pep 1 & $54-73$ & KPNNNKILVPKVSGLQYRVF & $60-68$ & ILVPKVSGL & 30 & $59-68$ & KILVPKVSGL & 14 \\
\hline Pep 2 & $392-422$ & HSMNSTILEDWNFGLQPPPGG & $398-406$ & ILEDWNFGL & 23 & $397-406$ & TILEDWNFGL & 16 \\
\hline Pep 3 & $62-81$ & VPKVSGLQYRVFRIHLPDPN & $67-75$ & GLQYRVFRI & 22 & $66-75$ & SGLQYRVFRI & 24 \\
\hline Pep 4 & $112-131$ & PLGVGISGHPLLNKLDDTEN & $118-126$ & SGHPLLNKL & 22 & $117-126$ & ISGHPLLNKL & 12 \\
\hline Pep 5 & 243-262 & GDSLFFYLRREQMFVRHLFN & 249-257 & YLRREQMFV & 22 & $248-257$ & FYLRREQMFV & 12 \\
\hline Pep 6 & $300-319$ & VTSDAQIFNKPYWLQRAQGH & $305-313$ & QIFNKPYWL & 21 & $305-313$ & QIFNKPYWL & 12 \\
\hline Pep 7 & $144-162$ & RECISMDYKQTQLCLIGCK & $148-156$ & SMDYKQTQL & 20 & $148-156$ & SMDYKQTQL & 11 \\
\hline Pep 8 & 293-312 & PTPSGSMVTSDAQIFNKPYW & 298-306 & SMVTSDAQI & 20 & 298-306 & SMVTSDAQI & 10 \\
\hline Pep 9 & $384-403$ & TADVMTYIHSMNSTILEDWN & $390-399$ & YIHSMNSTIL & 20 & 389-398 & TYIHSMNSTI & 23 \\
\hline Pep 10 & $152-171$ & KQTQLCLIGCKPPIGEHWG & $157-165$ & CLIGCKPPI & 23 & $156-165$ & LCLIGCKPPI & 12 \\
\hline
\end{tabular}

Scores indicate the prediction of peptide binding with HLA on MULTIPRED. Scores are not presented for the peptide binding in HLA-DR as each peptide listed binds with several types of HLA-DR and the scores are different among each type. Anchor residues for HLA class I are shown in bold. HPV, human papillomavirus; HLA, human leukocyte antigen; Pep, peptide.

available in all 10 individuals at other time points prior to and following vaccination.

Statistical analysis. The levels of $\operatorname{IgG}, \operatorname{IgM}, \operatorname{IgE}$ and $\operatorname{Ig} \mathrm{A}$ specific to HPV-16 L1-derived peptides were compared at the indicated time-points prior to and following the vaccination using Wilcoxon signed-rank test. All reported P-values were two-sided and statistically significant differences were indicated by $\mathrm{P}<0.05$. Comparison of $\mathrm{IgG}$ and $\mathrm{IgA}$ response was compared by analysis of variance. Analyses were performed with the use of JMP version 11 (SAS Institute Inc., Cary, NC, USA).

\section{Results}

IgG responses to HPV-16 L1-derived peptides subsequent to the HPV16/18 L1-VLP vaccination. Plasma samples obtained from the healthy females $(n=10)$ were examined for the levels of $\mathrm{IgG}$ reactive to each of the 10 different HPV16 L1-derived peptides before immunization and at 1,2, 7, 12 and 18 months after the first immunization with the HPV16/18 L1-VLP vaccine. As shown in Fig. 1, the IgG levels specific to Peptide 6 and Peptide 8 increased significantly at 2,7 and 12 months after the first immunization with the HPV16/18 L1-VLP vaccine (Peptide 6: $\mathrm{P}=0.002,0.004$ and 0.002, respectively; Peptide 8: $\mathrm{P}=0.002,0.002$ and 0.020 , respectively). A significant increase was also observed in the $\operatorname{IgG}$ levels specific to Peptide 4 after 2 and 7 months from the first immunization $(\mathrm{P}=0.002$ and 0.002, respectively; Fig. 1). The peptide-specific $\mathrm{IgG}$ responses peaked at 7 months after the first immunization (i.e. 1 month after the third immunization) and declined thereafter.

Comparison of IgM, IgE and IgA levels prior to and following vaccination. The $\operatorname{IgM}, \operatorname{IgE}$, and $\operatorname{Ig}$ A levels were then measured against HPV16 L1-derived peptides in plasma obtained from the healthy females $(n=10)$ before immunization and at 1,2 , 7, 12 and 18 months after the first immunization. As shown

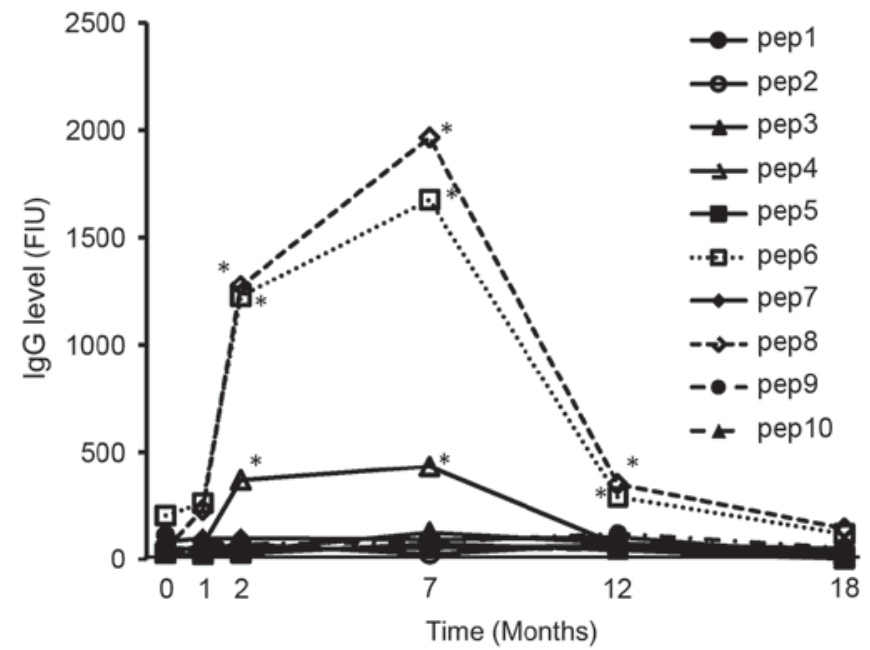

Figure 1. IgG responses (levels in FIU) to HPV16 L1-derived peptides following the HPV16/18 L1-VLP vaccination. The levels of IgG against HPV L1-derived 20-mer peptides were investigated in the plasma (100-fold dilution) of 10 healthy females at 1,2, 7, 12 and 18 months after the first immunization and compared with the levels before immunization. Median levels of IgG from the 10 healthy females are shown. ${ }^{*} \mathrm{P}<0.05$, vs. 0 months (before immunization; Wilcoxon rank-sum test). Ig, immunoglobulin; FIU, fluorescent intensity units; HPV, human papillomavirus; VLP, virus-like particle; Pep, peptide.

in Fig. 2, the $\operatorname{IgE}$ and $\operatorname{IgA}$ levels against Peptide 8 showed significant increase after 2 and 7 months from the first vaccination ( $\mathrm{IgE}$ : $\mathrm{P}=0.007$ and 0.029 , respectively; $\operatorname{IgA}: \mathrm{P}=0.001$ and 0.007 , respectively). In addition, IgA levels against Peptide 6 at 2 months after the first vaccination also demonstrated an increasing trend $(\mathrm{P}=0.080)$. IgE and IgA levels against Peptide 4 did not change significantly after any time of vaccination. However, there were no significant changes in the IgM levels against any peptides. Furthermore, the increase of $\mathrm{IgG}$ and IgA levels against Peptide 8 at 2 and 7 months after the first vaccination showed a positive correlation (Fig. 3). According 

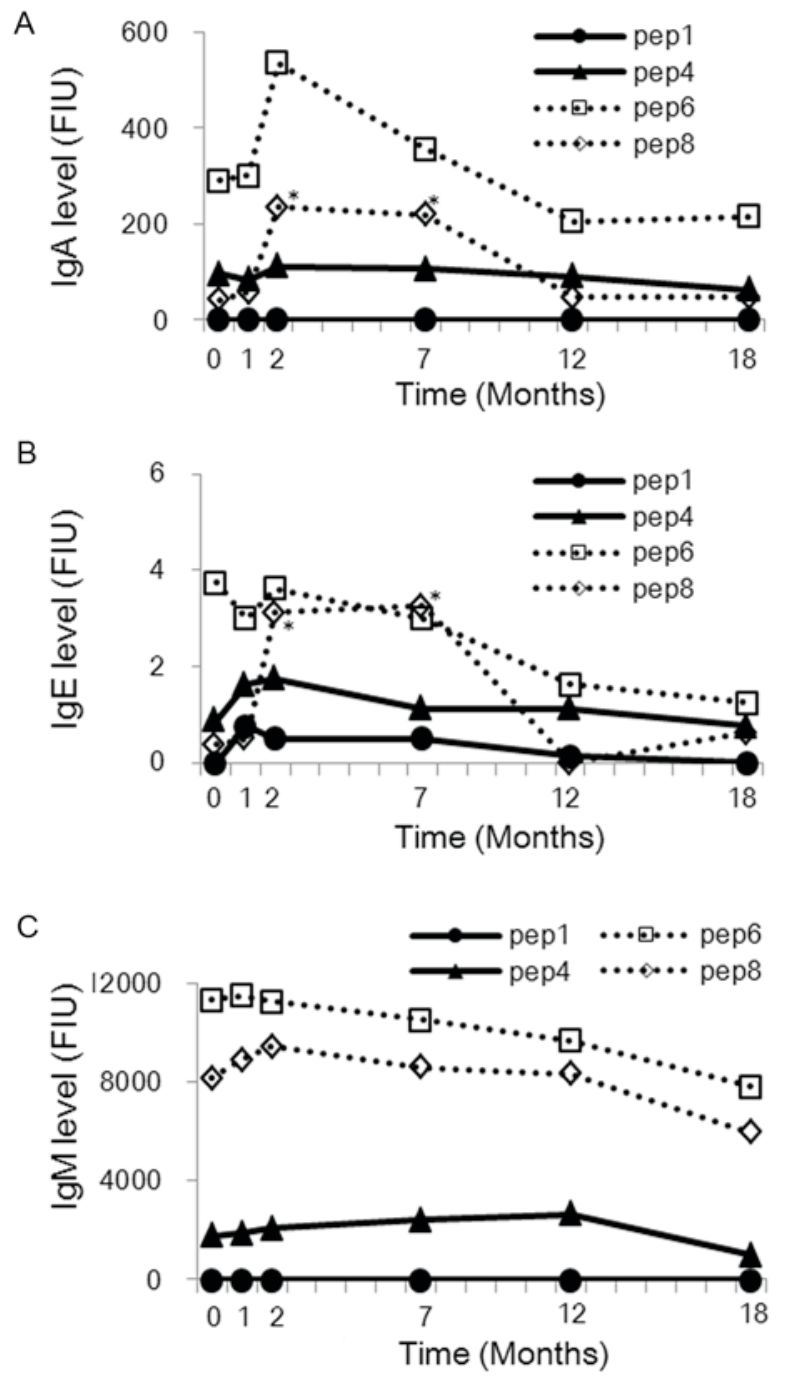

Figure 2. (A) $\operatorname{Ig} A$, (B) $\operatorname{IgE}$ and (C) IgM responses (levels in FIU) to HPV-16 L1-derived 20-mer peptides subsequent to the HPV16/18 L1-VLP vaccination. The levels in the plasma (100-fold dilution) were examined in 10 healthy females prior to immunization and at 1,2, 7, 12 and 18 months after the first immunization. Peptides 4, 6 and 8 were tested, since these induced IgG responses after immunization as shown Fig. 1, while Peptide 1 was used as the control. Median levels of IgM, IgE, and IgA from the 10 healthy females are shown. ${ }^{*} \mathrm{P}<0.05$, as determined by the Wilcoxon rank signed-rank test. Ig, immunoglobulin; FIU, fluorescent intensity units; HPV, human papillomavirus; VLP, virus-like particle; Pep, peptide.

to these findings, it is hypothesized that the overlapped position of Peptides 6 and 8 may be a B cell epitope.

Detailed B cell epitope mapping. To obtain further detailed information on immunogenic epitopes, the levels of IgG reactive to each of the 8 different 10 -mer peptides derived from the amino acid sequence between positions 295 and 325 of HPV16 L1 were determined, which contained the overlapped position of Peptide 6 and Peptide 8 sequences (position 300-312: VTSDAQIFNKPYW). As shown in Fig. 4, the IgG levels specific to the peptide at position 301-310 (TSDAQIFNKP) of HPV16 L1, but not specific to other 10-mer peptides, were significantly increased at 7 months after first vaccination compared with before vaccination $(\mathrm{P}=0.004)$. Notably, this amino acid sequence was shared by the immunogenic 20 -mer Peptides 6 and 8 .
$T$ cell responses specific to an HPV-16 L1-derived peptide in PBMCs subsequent to vaccination. T cell responses to an HPV16 L1-derived peptide at position 305-313 (QIFNKPYWL) of HPV16 L1 in the PBMC cultures before and after vaccinations were further assessed. The peptide at position 305-313 (QIFNKPYWL) of HPV16 L1 (was used in the current experiment since it was previously demonstrated that it binds well to both HLA-A*0201 and HLA-A*2402 (17). PBMCs were stimulated in vitro with specific or control peptides, and then their IFN- $\gamma$ production in response to the peptide-pulsed T2 $\left(\mathrm{HLA}-\mathrm{A} 2^{+}\right.$) or C1R-A24 (HLA-A24 ${ }^{+}$) cells was examined by ELISPOT assay. As shown in Fig. 5, the peptide-specific $\mathrm{T}$ cell responses at 1 month after the first immunization demonstrated significant increase compared with the response prior to vaccination $(\mathrm{P}=0.026)$. These results suggest that the HPV16/18 L1-VLP vaccination was able to induce specific immune responses in $\mathrm{T}$ and $\mathrm{B}$ cells simultaneously.

\section{Discussion}

In the present study, the humoral and cellular immune responses to HPV16 L1-derived peptides were analyzed in healthy females subsequent to immunization with the HPV16/18 L1-VLP vaccine. When B cell responses to 10 different 20 -mer peptides were screened, the levels of $\mathrm{IgG}$ of Peptides 6 and 8 were significantly elevated in the plasma at 2,7 and 12 months after first vaccination compared with before vaccination, and the levels of IgG of Peptide 4 were significantly elevated in the plasma at 2 and 7 months after first vaccination compared with before vaccination. Notably, the levels of $\operatorname{IgE}$ and $\operatorname{IgA}$ against Peptide 8 also revealed a significant increase at 2 and 7 months after the first vaccination, suggesting an isotype switch to $\mathrm{IgE}$ and $\operatorname{Ig}$ A. Similarly, the levels of IgA against Peptide 6 showed an increasing trend at 2 months after the first immunization. Although it is reported that the dominant antibody isotype in the cervical mucosa after immunization with HPV 16/18 L1-VLP is $\operatorname{IgG}, \operatorname{Ig}$ A is known to be the dominant antibody isotype in the mucosal immune system. Hence, IgA against the Peptide 6 and 8 may transudate and/or exudate from the systemic circulation to the cervical mucosa, and thus can be detectable in the mucosa after HPV16/18 L1-VLP vaccination.

Previously, we identified the B cell epitopes derived from HPV16 L1 in BALB/c and C57BL/6 N mice (17). Similar to the results obtained in humans in the present study, Peptide 6 was the major B cell epitope shared by female Balb/c (H-2d) and C57BL/6 N (H-2b) mice in our previous study (17). Nevertheless, detailed mapping analysis of B cell epitopes in humans indicated that a 10-mer peptide (TSDAQIFNKP) at the position 301-310 of HPV16 L1 was immunogenic, whereas another 10-mer peptide (AQIFNKPYWL) at position 304-313, which was identified as the B cell epitope in mice (17), was not immunogenic. This finding suggested that immunogenic B cell epitopes may be slightly different between mice and humans, although the reason for this discrepancy remains to be determined.

The present study also analyzed the $\mathrm{T}$ cell responses to an HPV16 L1-derived peptide (QIFNKPYWL), which was demonstrated to efficiently bind HLA-A2 and HLA-A24 (17), in females with HLA-A2 and/or HLA-A24 following immunization with the HPV16/18 L1-VLP vaccine. The results 

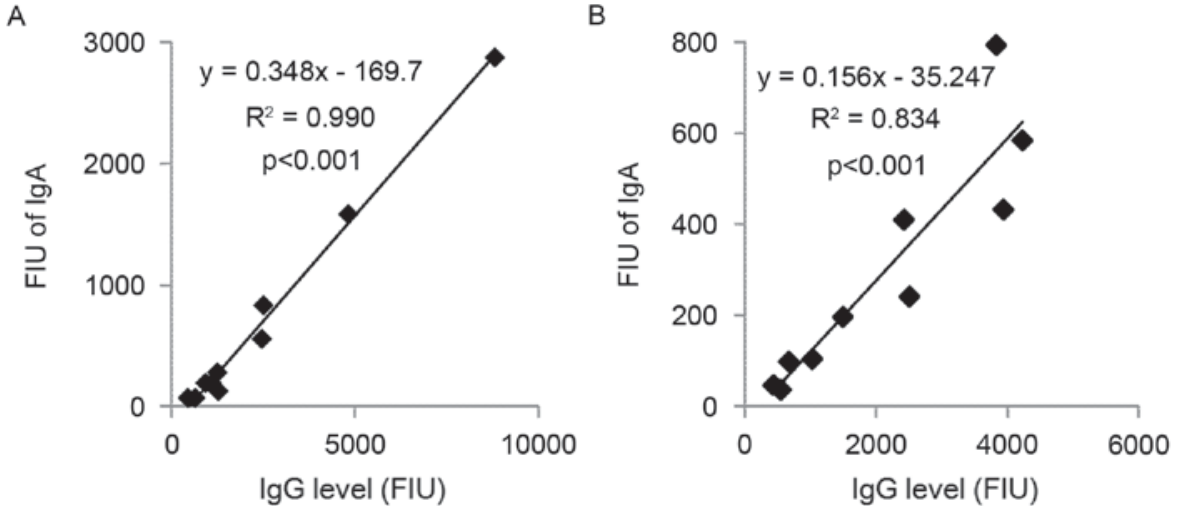

Figure 3. Detailed B cell epitope mapping comparison of $\operatorname{IgG}$ and IgA responses (levels in FIU) to Peptide 8 in 10 healthy females at (A) 2 months and (B) 7 months after the first vaccination, as compared by analysis of variance. Scattegrams of the levels of IgG and IgA are shown. Ig, immunoglobulin; FIU, fluorescent intensity units.

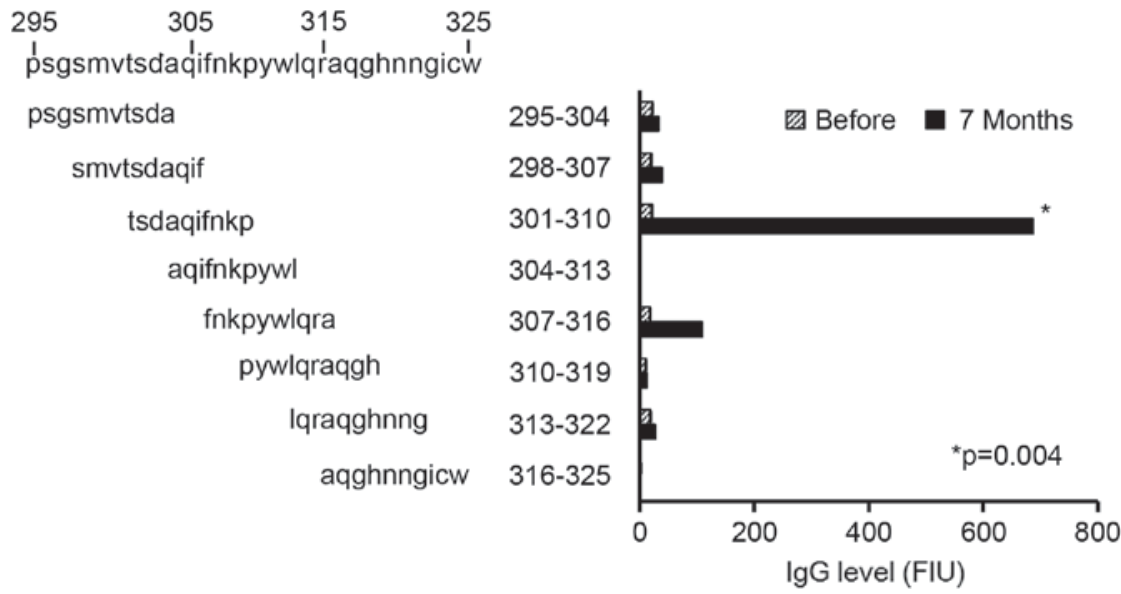

Figure 4. Detailed B cell epitope mapping. Plasma (100-fold dilution) was examined for IgG titers against HPV L1-derived 10-mer peptides in 10 healthy females before immunization and at 7 months after the first immunization. Median values of $\mathrm{IgG}$ titers from 10 healthy females are shown. "P<0.05 vs. before immunization (Wilcoxon rank-sum test). Ig, immunoglobulin; FIU, fluorescent intensity units; HPV, human papillomavirus.

HPV 16 L1 305-313

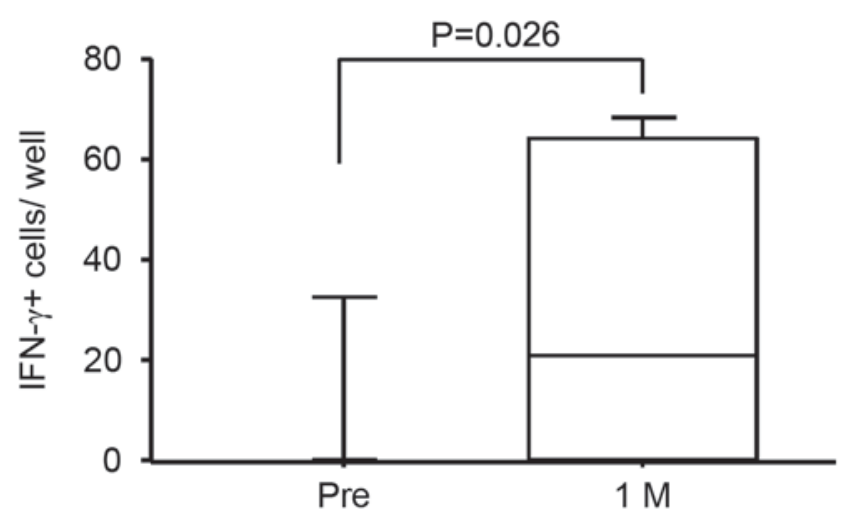

Figure 5. T cell response to HPV-16 L1-derived peptides following HPV16/18 L1-VLP vaccination. PBMCs from 10 healthy females before immunization and 1 month after the first immunization were stimulated five times in the presence of an HPV16 L1 (position 305-313; QIFNKPYWL) IFN- $\gamma$ production by PBMCs stimulated with HPV16 L1 (position 305-313) at 1 month after the first immunization were examined by ELISPOT assay. Means of spot numbers in 10 healthy females are shown. HPV, human papillomavirus; PBMC, peripheral blood mononuclear cell; VLP, virus-like particle. suggested that the HPV16/18 L1-VLP vaccination was able to induce specific immune responses in $\mathrm{T}$ and $\mathrm{B}$ cells simultaneously.

In the present study, the epitope recognized by B cells (TSDAQIFNKP) was not completely identical to that recognized by T cells (QIFNKPYWL); however, 6 out of 9 or 10 amino acids were shared by these two epitopes. Since it has been well recognized that cellular and humoral immune responses are crucial in the induction of effective immunity in animal models (19-21), simultaneous induction of both B and $\mathrm{T}$ cell responses against HPV16 L1 may be important for efficient prevention of HPV infection and subsequent HPV-associated neoplasia.

In conclusion, a 10-mer amino acid sequence (TSDAQIFNKP) derived from HPV16 L1 was identified in the present study as an immunogenic B cell epitope in the females after HPV16/18 L1-VLP immunization. In addition, T cell responses to another HLA-A2- and HLA-A24-restricted epitope (QIFNKPYWL) derived from HPV16 L1 in the vaccinated individuals were detected. The identified $\mathrm{B}$ and $\mathrm{T}$ cell epitopes may be useful for monitoring the immune responses to HPV16/18 L1-VLP subsequent to vaccination. Whether the 
vaccine-induced $\operatorname{Ig} \mathrm{G}$ and/or $\operatorname{Ig} \mathrm{A}$ response to the identified B cell epitope possesses the biological activity to neutralize the HPV infection and/or facilitate the prophylactic effect of the HPV 16/18 L1 vaccine remains to be clarified in the near future. However, the present study may provide novel information for better understanding the immune responses to HPV 16 L1-VLP vaccines.

\section{Acknowledgements}

The present research was supported in part by The Fukuoka Obgyn Researcher's Charity Foundation Fund, Japan.

\section{References}

1. International Agency for Research on Cancer. (2012) Globocan 2012: Estimated cancer incidence, mortality and prevalence worldwide in 2012. http://globocan.iarc.fr/Pages/fact_sheets_ cancer.aspx. Accessed 27 November 2016.

2. Muñoz N, Bosch FX, de Sanjosé S, Herrero R, Castellsagué X, Shah KV, Snijders PJ and Meijer CJ; International agency for research on cancer multicenter cervical cancer study group. Epidemiologic classification of human papillomavirus types associated with cervical cancer. N Engl J Med 348: 518-527, 2003.

3. Li N, Franceschi S, Howell-Jones R, Snijders PJ and Clifford GM: Human papillomavirus type distribution in 30,848 invasive cervical cancers worldwide: Variation by geographical region, histological type and year of publication. Int J Cancer 128: 927-935, 2010.

4. Wingo PA, Cardinez CJ, Landis SH, Greenlee RT, Ries LA, Anderson RN and Thun MJ: Long-term trends in cancer mortality in the United States, 1930-1998. Cancer 97: 3133-3275, 2003.

5. Villa LL, Costa RL,Petta CA, Andrade RP, AultKA, Giuliano AR, Wheeler CM, Koutsky LA, Malm C, Lehtinen M, et al: Prophylactic quadrivalent human papillomavirus (types 6,11 , 16, and 18) L1 virus-like particle vaccine in young women: A randomised double-blind placebo-controlled multicentre phase II efficacy trial. Lancet Oncol 6: 271-278, 2005.

6. Harper DM, Franco EL, Wheeler C, Ferris DG, Jenkins D, Schuind A, Zahaf T, Innis B, Naud P, De Carvalho NS, et al: Efficacy of a bivalent L1 virus-like particle vaccine in prevention of infection with human papillomavirus types 16 and 18 in young women: A randomised controlled trial. Lancet 364: 1757-1765, 2004.

7. Garland SM, Hernandez-Avila M, Wheeler CM, Perez G, Harper DM, Leodolter S, Tang GW, Ferris DG, Steben M, Bryan J, et al: Quadrivalent vaccine against human papillomavirus to prevent anogenital diseases. N Engl J Med 356 1928-1943, 2007.

8. Paavonen J, Naud P, Salmerón J, Wheeler CM, Chow SN, Apter D, Kitchener H, Castellsague X, Teixeira JC, Skinner SR, et al: Efficacy of human papillomavirus (HPV)-16/18 AS04-adjuvanted vaccine against cervical infection and precancer caused by oncogenic HPV types (PATRICIA): Final analysis of a double-blind, randomised study in young women. Lancet 374: 301-314, 2009.
9. Roteli-Martins CM, Naud P, De Borba P, Teixeira JC, De Carvalho NS, Zahaf T, Sanchez N, Geeraerts B and Descamps D: Sustained immunogenicity and efficacy of the HPV-16/18 AS04-adjuvanted vaccine: Up to 8.4 years of follow-up. Hum Vaccin Immunother 8: 390-397, 2012

10. Rowhani-Rahbar A, Alvarez FB, Bryan JT, Hughes JP, Hawes SE, Weiss NS and Koutsky LA: Evidence of immune memory 8.5 years following administration of a prophylactic human papillomavirus type 16 vaccine. J Clin Virol 53: 239-243, 2012.

11. Joura EA, Kjaer SK, Wheeler CM, Sigurdsson K, Iverson OE, Hernandez-Ailta M, Perez G, Brown DR, Koutsky LA, Tay EH, et al: HPV antibody levels and clinical efficacy following administration of a prophylactic quadrivalent HPV vaccine. Vaccine 26: 6844-6851, 2008.

12. Ryding J, Dahlberg L, Wallen-Ohman M and Dilner J: Deletion of a major epitope of human papillomavirus tyle16 virus-like particles. J Gen Virol 88: 792-802, 2007.

13. Kirnbauer R, Hubbert NL, Wheeler CM, Becker TM, Lowy DR and Schiller JT: A virus-like particle enzyme-linked immunosorbent assay detects serum antibodies in a majority of women infected with human papillomavirus type 16. J Natl Cancer Inst 86: 494-499, 1994.

14. Pastrana DV, Buck CB, Pang YY, Thompson CD, Castle PE, FitzGerald PC, Kruger Kjaer S, Lowy DR and Schiller JT: Reactivity of human sera in a sensitive, high-throughput pseudovirus-based papillomavirus neutralization assay for HPV16 and HPV18. Virology 321: 205-216, 2004.

15. Dias D, Van Doren JV, Schlottmann S, Kelly S, Puchalski D, Ruiz W, Boerckel P, Kessler J, Antonello JM, Green T, et al: Optimization and validation of a multiplexed luminex assay to quantify antibodies to neutralizing epitopes on human papillomaviruses 6, 11, 16, and 18. Clin Diagn Lab Immunol 12: 959-969, 2005.

16. Waterboer T, Sehr P, Michael KM, Franceschi S, Nieland JD, Joos TO, Templin MF and Pawlita M: Multiplex human papillomavirus serology based on in situ-purified glutathione S-transferase fusion proteins. Clin Chem 51: 1845-1853, 2005.

17. Fukui A, Matsueda S, Kawano K, Tsuda N, Komatsu N, Shichijo S, Sasada T, Hattori S, Ushijima K, Itoh K and Kamura T: Identification of B cell epitopes reactive to human papillomavirus type-16 L1-derived peptides. Virol J 9: 199, 2012.

18. Komatsu N, Shichijo S, Nakagawa M and Itoh K: New multiplexed flow cytometric assay to measure anti-peptide antibody: A novel tool for monitoring immune responses to peptides used for immunization. Scand J Clin Lab Invest 64: 535-546, 2004.

19. AvogadriF,Merghoub T,Maughan MF,Hirschhorn-Cymerman D, Morris J Ritter E, Olmsted R, Houghton AN and Wolchok JD: Alphavirus replicon particles expressing TRP-2 provide potent therapeutic effect on melanoma through activation of humoral and cellular immunity. PLoS One 5: e12670, 2010.

20. Hong S, Qian J, Li H, Yang J, Lu Y, Zheng Y and Yi Q: CpG or IFN- $\alpha$ are more potent adjuvants than GM-CSF to promote anti-tumor immunity following idiotype vaccine in multiple myeloma. Cancer Immunol Immunother 6: 561-571, 2012.

21. Cubillos C, de la Torre BG, Bárcena J, Andreu D, Sobrino F and Blanco E: Inclusion of a specific $T$ cell epitope increases the protection conferred against foot-and-mouth disease virus in pigs by a linear peptide containing an immunodominant $\mathrm{B}$ cell site. Virol J 9: 66, 2012. 